\title{
An analytical solution simulating growth of Lewy bodies
}

\author{
Ivan A. Kuznetsov $^{(\mathrm{a}),(\mathrm{b})}$ and Andrey V. Kuznetsov ${ }^{(\mathrm{c})}$ \\ (a) Perelman School of Medicine, University of Pennsylvania, Philadelphia, PA 19104, USA \\ (b) Department of Bioengineering, University of Pennsylvania, Philadelphia, PA 19104, USA \\ ${ }^{(c)}$ Department of Mechanical and Aerospace Engineering, North Carolina State University, \\ Raleigh, NC 27695-7910, USA; e-mail: avkuznet@ncsu.edu
}

\begin{abstract}
This paper reports a minimal model simulating the growth of a Lewy body (LB). To the best of our knowledge, this is the first model simulating Lewy body growth. The LB is assumed to consist of a central spherical core, which is composed of membrane fragments and various dysfunctional intracellular organelles, and a halo, which is composed of alpha-synuclein fibrils. Membrane fragments and alphasynuclein monomers are assumed to be produced in the soma at constant rates. The growth of the core and the halo are simulated by the Finke-Watzky model. Analytical solutions describing the growth of the core and the halo are obtained.
\end{abstract}

Keywords neuron; Parkinson's disease; Lewy body dementia; mathematical modeling; alpha-synuclein 


\section{Introduction}

The formation of Lewy bodies (LBs) in the soma of dopaminergic neurons is one of the main characteristic features of Parkinson's disease (PD) [1-3]. Until recently it was believed that LBs mostly consist of misfolded forms of alpha-synuclein ( $\alpha$-syn) [4]. However, new data reported in [5] show that LBs are mostly composed of various lipid components, membrane fragments, organelles, vesicular structures, dysmorphic mitochondria, autophagosome precursors, and lysosomes. The reasons for this surprising observation and the question of whether $\alpha$-syn fibrils are a part of LBs are heavily debated $[6,7]$.

In this paper, we develop a model that can help shed light on these previous observations. It is known that brainstem-type LBs consist of a dense core surrounded by a halo composed of radiating filaments $[3,7]$. The halo resembles a spherical shell. LBs are likely formed from their precursors, pale bodies, which are the granular structures that lack a halo [7]. A pale body can progress to become a classical LB with a halo [8].

It is still debated whether LBs are neurotoxic or neuroprotective. A large body of research argues that LBs are cytotoxic [9]. On the other hand, many researchers support the view that LBs remove cytotoxic or unwanted species from the cytosol and thus are neuroprotective [10]. Ref. [11] reported that in PD the loss of neurons in the ventrolateral tier of the pars compacta of the substantia nigra (SN) is much higher than the number of LBs. LB-containing neurons seem to be morphologically healthier than neighboring non-LB-containing neurons. It seems that most SN neurons that die of apoptosis do not contain LBs. On the other hand, ref. [8] noted that if LBs are neuroprotective, it is hard to explain why as PD progresses the number of neurons with LBs in SN pars compacta does not increase. Instead, LB-laden neurons die. To address this paradox, in our model we assumed that the process of formation of LBs includes two stages. First, a structure composed of membranous fragments, organelles, vesicular structures, and various lipid constituents is formed by aggregation of these components into the core of an LB. We assumed that the core is benign to the neuron. Then, surface-initiated polymerization [12] induced by the surface of the core leads to the growth of $\alpha$-syn fibrils that form the halo of the LB (Fig. 1). $\alpha$-syn fibrils elongate by adding $\alpha$-syn monomers from the cytosol. We assumed that radiating $\alpha$-syn filaments are cytotoxic. These radiating filaments also prevent further growth of the core by cutting off the supply of membrane fragments to the core, thus blocking broken intracellular material from being removed from the cytosol by incorporating it into the core of the LB. 
In this paper, we develop a mathematical model based on these assumptions and obtain its analytical solution.

\section{Materials and models}

\subsection{Governing equations}

Independent variables in the model are summarized in Table 1, dependent variables in the model are summarized in Table 2, and parameters involved in the model are summarized in Table 3.

Since the formation of LBs is a very slow process, we assumed that it is limited by the kinetics of two aggregation processes: first, by the kinetics of membrane fragment aggregation into the LB core and then by the kinetics of $\alpha$-syn fibril growth that forms the LB halo.

A minimalistic 2-step Finke-Watzky (F-W) model describes continuous nucleation followed by fast, autocatalytic surface growth. This model is described by the following transitions:

$$
A \stackrel{k_{1}}{\longrightarrow} B
$$

$A+B \stackrel{k_{2}}{\longrightarrow} 2 B$

Usually, the F-W model is applied to simulate the conversion of a given initial concentration of monomers, $[A]_{0}$, into polymers, $[B]$. Analytical solutions for such cases are reported, for example, in [13]. Here we apply the F-W model to a different situation. Results reported in [5] and the analysis reported in [7] suggest that the core of the LB is composed of lipid membrane fragments, damaged organelles, lysosomes, and damaged mitochondria. Hereafter, for briefness, we will use the term membrane fragments to denote any fragmented/damaged components that can form the core of an LB.

We assume that membrane fragments are produced at a rate $q_{F R}$ in the soma. Stating the conservation of membrane fragments in the soma results in the following equation:

$\frac{d\left[A_{F R}\right]}{d t}=\frac{q_{F R}}{V_{\text {soma }}} a_{21}-k_{1, F R}\left[A_{F R}\right]-k_{2, F R}\left[A_{F R}\right]\left[B_{F R}\right]$,

where $a_{21}=10^{21} \frac{\mu \mathrm{M} \mu \mathrm{m}^{3}}{\mathrm{~mol}}$ is the conversion factor from $\frac{\mathrm{mol}}{\mu \mathrm{m}^{3}}$ to $\mu \mathrm{M}$.

Stating the conservation of membrane aggregates in the soma, which form the core of the LB, leads to the following equation: 
$\frac{d\left[B_{F R}\right]}{d t}=k_{1, F R}\left[A_{F R}\right]+k_{2, F R}\left[A_{F R}\right]\left[B_{F R}\right]$

Eqs. (3) and (4) are solved subject to the following initial condition:

At $t=0: \quad\left[A_{F R}\right]=\left[A_{F R}\right]_{0},\left[B_{F R}\right]=0$.

By adding Eqs. (3) and (4) and integrating the result with respect to time, the following is obtained:

$\left[A_{F R}\right]+\left[B_{F R}\right]=\left[A_{F R}\right]_{0}+\frac{q_{F R}}{V_{\text {soma }}} a_{21} t$

The increase of $\left[A_{F R}\right]+\left[B_{F R}\right]$ with time is due to the production of membrane fragments in the soma.

Eliminating $\left[A_{F R}\right]$ from Eq. (4) by using Eq. (6), the following is obtained:

$$
\begin{aligned}
& \frac{d\left[B_{F R}\right]}{d t}=k_{1, F R}\left(\left[A_{F R}\right]_{0}+\frac{q_{F R}}{V_{\text {soma }}} a_{21} t-\left[B_{F R}\right]\right) \\
& +k_{2, F R}\left(\left[A_{F R}\right]_{0}+\frac{q_{F R}}{V_{\text {soma }}} a_{21} t-\left[B_{F R}\right]\right)\left[B_{F R}\right]
\end{aligned}
$$

The solution of Eq. (7) subject to initial condition (5b) is

$$
\left[B_{F R}\right]=\frac{k_{1, F R}}{k_{2, F R}}
$$

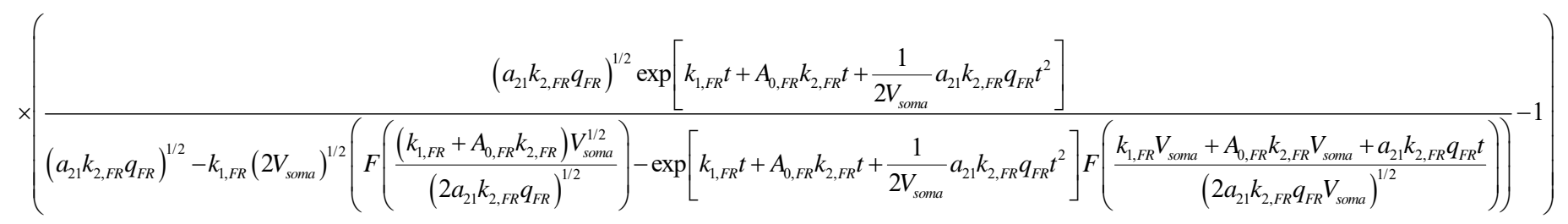

Here $F(x)$ is Dawson's integral:

$$
F(x)=\frac{1}{2} \sqrt{\pi} e^{-x^{2}} \operatorname{erfi}(x)
$$

where $\operatorname{erfi}(x)$ is the imaginary error function.

The growth of the core of an LB (Fig. 1) is simulated as follows. The volume of the core of the LB can be found as: 
$V_{L B}=\frac{\left[B_{F R}\right]}{a_{21}} N_{A} V_{\text {soma }} V_{F R, a v}=\frac{4}{3} \pi r_{L B}^{3}$

where

$V_{\text {soma }}=\frac{1}{6} \pi D_{\text {soma }}^{3}$

is the volume of the soma and

$V_{F R, a v}=\frac{1}{6} \pi D_{F R, a v}^{3}$

is the average volume of a lipid membrane fragment.

This is consistent with [14], which pointed out that the volume of a nanoparticle is proportional to the number of monomers making up the particle. Hence, the size of a nanoparticle is proportional to the cubic root of the number of monomers composing the particle.

The growth continues until $r_{L B}$ reaches $r_{L B, f}$, where

$r_{L B, f}=\left(\frac{\left[B_{F R}\right]}{a_{21}} N_{A} V_{\text {soma }} V_{F R, a v} /\left(\frac{4}{3} \pi\right)\right)^{1 / 3}$.

We assumed that $\alpha$-syn monomers are produced at a rate $q_{A S}$ in the soma. We also assumed that $\alpha$-syn fibrils are produced by the polymerization of $\alpha$-syn monomers in the halo region of the LB. The F-W model is utilized again. Stating the conservation of $\alpha$-syn monomers in the soma results in the following equation:

$\frac{d\left[A_{A S}\right]}{d t}=\frac{q_{A S}}{V_{\text {soma }}} a_{21}-k_{1, A S}\left[A_{A S}\right]-k_{2, A S}\left[A_{A S}\right]\left[B_{A S}\right]$.

Stating the conservation of $\alpha$-syn fibrils, which form the halo region of the LB, leads to the following equation:

$\frac{d\left[B_{A S}\right]}{d t}=k_{1, A S}\left[A_{A S}\right]+k_{2, A S}\left[A_{A S}\right]\left[B_{A S}\right]$.

Eqs. (14) and (15) are solved subject to the following initial condition:

At $t=t_{L B, f}: \quad\left[A_{A S}\right]=\left[A_{A S}\right]_{0},\left[B_{A S}\right]=0$. 
The initial value problem described by Eqs. (14)-(16) becomes similar to that described by Eqs. (3)-(5) if the transformation

$\hat{t}=t-t_{L B, f}$

is utilized.

By adding Eqs. (14) and (15) and integrating the result with respect to time, the following is obtained:

$\left[A_{A S}\right]+\left[B_{A S}\right]=\left[A_{A S}\right]_{0}+\frac{q_{A S}}{V_{\text {soma }}} a_{21} \hat{t}$

The increase of $\left[A_{A S}\right]+\left[B_{A S}\right]$ with time is due to the production of membrane fragments in the soma.

Eliminating $\left[A_{A S}\right]$ from Eq. (15) by using Eq. (18), the following is obtained:

$$
\begin{aligned}
& \frac{d\left[B_{A S}\right]}{d t}=k_{1, A S}\left(\left[A_{A S}\right]_{0}+\frac{q_{A S}}{V_{\text {soma }}} a_{21} \hat{t}-\left[B_{A S}\right]\right) \\
& +k_{2, A S}\left(\left[A_{A S}\right]_{0}+\frac{q_{A S}}{V_{\text {soma }}} a_{21} \hat{t}-\left[B_{A S}\right]\right)\left[B_{A S}\right]
\end{aligned}
$$

The solution of Eq. (19) subject to initial condition (16b) is

$$
\begin{aligned}
& {\left[B_{A S}\right]=\frac{k_{1, A S}}{k_{2, A S}}} \\
& \times\left(\frac{\left(a_{21} k_{2, A S} q_{A S}\right)^{1 / 2} \exp \left[k_{1, A S} \hat{t}+A_{0, A S} k_{2, A S} \hat{t}+\frac{1}{2 V_{\text {soma }}} a_{21} k_{2, A S} q_{A S} \hat{t}^{2}\right]}{\left(a_{21} k_{2, A S} q_{A S}\right)^{1 / 2}-k_{1, A S}\left(2 V_{\text {soma }}\right)^{1 / 2}\left(F\left(\frac{\left(k_{1, A S}+A_{0, A S} k_{2, A S}\right) V_{\text {soma }}^{1 / 2}}{\left(2 a_{21} k_{2, A S} q_{A S}\right)^{1 / 2}}\right)-\exp \left[k_{1, A S} \hat{t}+A_{0, A S} k_{2, A S} \hat{t}+\frac{1}{2 V_{\text {soma }}} a_{21} k_{2, A S} q_{A S} \hat{t}^{2}\right] F\left(\frac{k_{1, A S} V_{\text {soma }}+A_{0, A S} k_{2, A S} V_{\text {soma }}+a_{21} k_{2, A S} q_{A S} \hat{t}}{\left(2 a_{21} k_{2, A S} q_{A S} V_{\text {soma }}\right)^{1 / 2}}\right)\right.}-1\right)
\end{aligned}
$$

The thickness of the halo of the LB (Fig. 1) in the radial direction can then be found as:

$$
r_{H}-r_{L B, f}=\frac{\left[B_{A S}\right]}{a_{21}} N_{A} V_{\text {soma }} L_{A S, \text { mon }} / N_{\text {mon }} .
$$

Table 1. Independent variables in the model.

\begin{tabular}{|l|l|l|}
\hline Symbol & Definition & Units \\
\hline
\end{tabular}




\begin{tabular}{|l|l|l|}
\hline$t$ & Time & $\mathrm{s}$ \\
\hline
\end{tabular}

Table 2. Dependent variables in the model.

\begin{tabular}{|l|l|l|}
\hline Symbol & Definition & Units \\
\hline$\left[A_{F R}\right]$ & $\begin{array}{l}\text { Molar concentration of lipid membrane } \\
\text { fragments (as well as damaged organelles, } \\
\text { lysosomes, and damaged mitochondria; } \\
\text { generally, any fragments that can form the core } \\
\text { of the LB) in the soma }\end{array}$ & $\mu \mathrm{M}$ \\
\hline$\left[B_{F R}\right]$ & $\begin{array}{l}\text { Molar concentration of aggregated lipid } \\
\text { membrane fragments in the core of the LB }\end{array}$ & $\mu \mathrm{M}$ \\
\hline$\left[A_{A S}\right]$ & $\begin{array}{l}\text { Molar concentration of } \alpha \text {-syn monomers in the } \\
\text { soma }\end{array}$ & $\mu \mathrm{M}$ \\
\hline$\left[B_{A S}\right]$ & $\begin{array}{l}\text { Molar concentration of } \alpha \text {-syn fibrils in the halo } \\
\text { of the LB }\end{array}$ & $\mu \mathrm{M}$ \\
\hline
\end{tabular}

Table 3. Parameters involved in the model.

\begin{tabular}{|l|l|l|l|l|l|}
\hline Symbol & Definition & Units & $\begin{array}{l}\text { Value or } \\
\text { range }\end{array}$ & $\begin{array}{l}\text { Reference or } \\
\text { estimation method }\end{array}$ & $\begin{array}{l}\text { Value(s) used in } \\
\text { computations }\end{array}$ \\
\hline$\left[A_{F R}\right]_{0}$ & $\begin{array}{l}\text { Initial concentration } \\
\text { of lipid membrane } \\
\text { fragments in the } \\
\text { soma }\end{array}$ & $\mu \mathrm{M}$ & & & 0 \\
\hline$\left[A_{A S}\right]_{0}$ & $\begin{array}{l}\text { Initial concentration } \\
\text { of } \alpha \text {-syn monomers in } \\
\text { the soma }\end{array}$ & $\mu \mathrm{M}$ & & & 0 \\
\hline$D_{\text {soma }}$ & \begin{tabular}{l} 
Diameter of the soma \\
\hline
\end{tabular} & $\mu \mathrm{m}$ & $20^{\text {a }}$ & & 20 \\
\hline
\end{tabular}




\begin{tabular}{|c|c|c|c|c|c|}
\hline$D_{F R, a v}$ & $\begin{array}{l}\text { Average size of a } \\
\text { lipid membrane } \\
\text { fragment }\end{array}$ & $\mu \mathrm{m}$ & $0.2^{b}$ & {$[5,15]$} & 0.2 \\
\hline$k_{1, F R}$ & $\begin{array}{l}\text { Rate constant for the } \\
\text { first } \\
\text { pseudoelementary } \\
\text { step of the F-W } \\
\text { model describing } \\
\text { nucleation of } \\
\text { aggregates composed } \\
\text { of lipid membrane } \\
\text { fragments in the } \\
\text { soma }\end{array}$ & $\mathrm{s}^{-1}$ & & & $3 \times 10^{-7}$ \\
\hline$k_{2, F R}$ & $\begin{array}{l}\text { Rate constant for the } \\
\text { second } \\
\text { pseudoelementary } \\
\text { step of the F-W } \\
\text { model describing } \\
\text { autocatalytic } \\
\text { attachment of lipid } \\
\text { membrane fragments } \\
\text { to the LB core }\end{array}$ & $\mu \mathrm{M}^{-1} \mathrm{~s}^{-1}$ & & & $2 \times 10^{-6}$ \\
\hline$k_{1, A S}$ & $\begin{array}{l}\text { Rate constant for the } \\
\text { first } \\
\text { pseudoelementary } \\
\text { step of the F-W } \\
\text { model describing } \\
\text { nucleation of } \alpha \text {-syn } \\
\text { aggregates }\end{array}$ & $\mathrm{s}^{-1}$ & $\begin{array}{l}2.78 \times 10^{-7}- \\
9.44 \times 10^{-5}\end{array}$ & [16] & $3 \times 10^{-7}$ \\
\hline$k_{2, A S}$ & $\begin{array}{l}\text { Rate constant for the } \\
\text { second }\end{array}$ & $\mu \mathrm{M}^{-1} \mathrm{~s}^{-1}$ & $1.19 \times 10^{-6}-$ & [16] & $2 \times 10^{-6}$ \\
\hline
\end{tabular}




\begin{tabular}{|c|c|c|c|c|c|}
\hline & $\begin{array}{l}\text { pseudoelementary } \\
\text { step of the F-W } \\
\text { model describing } \\
\text { autocatalytic growth } \\
\text { of } \alpha \text {-syn fibrils due to } \\
\text { attachment of } \alpha \text {-syn } \\
\text { monomers to the } \\
\text { fibrils in the LB halo }\end{array}$ & & $5.00 \times 10^{-6}$ & & \\
\hline$L_{A S, \text { mon }}$ & $\begin{array}{l}\text { Length of an } \alpha \text {-syn } \\
\text { monomer }\end{array}$ & $\mu \mathrm{m}$ & $0.05^{\mathrm{c}}$ & {$[17]$} & 0.05 \\
\hline$N_{A}$ & Avogadro's number & $\mathrm{mol}^{-1}$ & $6.022 \times 10^{23}$ & & $6.022 \times 10^{23}$ \\
\hline$N_{\text {mon }}$ & $\begin{array}{l}\text { Number of } \alpha \text {-syn } \\
\text { monomers in a fibril } \\
\text { cross-section }\end{array}$ & & $400^{d}$ & {$[17,18]$} & \\
\hline$q_{F R}$ & $\begin{array}{l}\text { Rate of generation of } \\
\text { lipid membrane } \\
\text { fragments in the } \\
\text { soma }\end{array}$ & $\mathrm{mol} \mathrm{s}^{-1}$ & & & $5 \times 10^{-27}$ \\
\hline$q_{\mathrm{AS}}$ & $\begin{array}{l}\text { Rate of production of } \\
\alpha \text {-syn monomers in } \\
\text { the soma }\end{array}$ & $\mathrm{mol} \mathrm{s}^{-1}$ & & & $5 \times 10^{-27}$ \\
\hline$t_{L B, f}$ & $\begin{array}{l}\text { Duration of LB core } \\
\text { growth }\end{array}$ & $\mathrm{s}$ & $1.58 \times 10^{7} \mathrm{e}$ & {$[11]$} & $1.58 \times 10^{7}$ \\
\hline$t_{H, f}$ & $\begin{array}{l}\text { Duration of LB halo } \\
\text { growth }\end{array}$ & $\mathrm{s}$ & $3.15 \times 10^{7} \mathrm{f}$ & [11] & $3.15 \times 10^{7}$ \\
\hline
\end{tabular}

${ }^{\text {a }}$ We considered a representative neuron with a soma diameter of $20 \mu \mathrm{m}$.

${ }^{\mathrm{b}}$ A representative membranous inclusion size found in LBs, based on figures reported in [5], is $200 \mathrm{~nm}$.

Although membranous material is present in LBs in different forms, as an estimate of the volume of a 
representative membrane fragment aggregate we assumed that it was approximately a sphere with a diameter of $200 \mathrm{~nm}$. This is consistent with [15], who reported that sliced membrane fragments selfassembled into spherical nanovesicles with a diameter of 100-300 $\mathrm{nm}$.

${ }^{c}$ The length of a fully extended $\alpha$-syn monomeric chain is $\sim 50 \mathrm{~nm}[17]$.

${ }^{\mathrm{d}}$ The typical diameter of $\alpha$-syn filaments is $6-10 \mathrm{~nm}$ and the diameter of an $\alpha$-syn monomer is $0.4 \mathrm{~nm}$ $[17,18]$. Hence, $(8 / 0.4)^{2}=400$.

${ }^{\mathrm{e}}$ The life span of LBs is approximately six months [11].

${ }^{\mathrm{f}}$ We assumed that the LB halo starts growing at $t=t_{L B, f}$ and ends growing at $t=t_{H, f}$ (at this point the neuron dies).

\subsection{Sensitivity analysis}

We investigated how the outer halo radius at the end of the simulation $\left(t_{H, f}=1\right.$ year $)$ depends on various model parameters. To perform this analysis, we computed the local sensitivity coefficients, which are first-order partial derivatives of the outer halo radius with respect to the parameters [19-22]. The sensitivity coefficient of $r_{H, f}$ to parameter $q_{F R}$, for example, was calculated as follows:

$$
\left.\frac{\partial r_{H, f}}{\partial q_{F R}} \approx \frac{r_{H, f}\left(q_{F R}+\Delta q_{F R}\right)-r_{H, f}\left(q_{F R}\right)}{\Delta q_{F R}}\right|_{\text {other parmeters kept constant }},
$$

where $\Delta q_{F R}=10^{-3} q_{F R}$ is the step size. To test the independence of the sensitivity coefficients to the step size we tested various step sizes.

Non-dimensionalized relative sensitivity coefficients were calculated following $[20,23]$ as, for example:

$$
S_{q_{F R}}^{r_{H, f}}=\frac{q_{F R}}{r_{H, f}} \frac{\partial r_{H, f}}{\partial q_{F R}}
$$

\section{Results}

\subsection{Analysis of the model}

The increase of the generation rate of lipid membrane fragments, $q_{F R}$, leads to an increase in the concentration of these fragments in the soma (Fig. 2a) and faster growth of the core of the LB (Fig. 2b). 
After six months of growth, the LB lipid core reaches a diameter that is in the range $5.02 \mu \mathrm{m}-8.03 \mu \mathrm{m}$, depending on the value of $q_{F R}$. After another six months (the total time of LB growth is assumed to be one year, after that the neuron dies), the outer diameter of the halo reaches $9.80 \mu \mathrm{m}-12.8 \mu \mathrm{m}$, which is consistent with the 8-30 $\mu \mathrm{m}$ range of LB diameter reported in [10].

An increase in the rate of production of $\alpha$-syn monomers in the soma, $q_{A S}$, leads to an increase in the concentration of $\alpha$-syn monomers in the soma (Fig. 3a) and faster growth of the LB halo (Fig. 3b). After six months of growth, the diameter of the LB core reaches $6.34 \mu \mathrm{m}$. After another six months, the outer diameter of the halo reaches $8.71 \mu \mathrm{m}-16.1 \mu \mathrm{m}$, depending on the value of $q_{A S}$.

An increase in the rate constant for the first pseudoelementary step of the F-W model describing nucleation of aggregates composing lipid membrane fragments in the soma, $k_{1, F R}$, results in faster nucleation of such aggregates (Fig. 4a). This leads to faster growth of the LB core (Fig. 4b). After six months of growth, the diameter of the LB core reaches $5.89 \mu \mathrm{m}-6.58 \mu \mathrm{m}$, depending on the value of $k_{1, F R}$. After another six months, the outer diameter of the halo reaches $10.7 \mu \mathrm{m}-11.4 \mu \mathrm{m}$.

An increase in the rate constant for the second pseudoelementary step of the F-W model describing autocatalytic attachment of lipid membrane fragments to the LB core, $k_{2, F R}$, increases the rate of membrane fragment aggregation in the LB core (Fig. 5a). This results in faster growth of the core (Fig. $5 b)$. It should be noted that for given parameter values the solution is less sensitive to $k_{2, F R}$, and to produce visibly distinct curves in Fig. 5 we had to increase the value of $k_{2, F R}$ by a factor of $10^{3}$. After six months of growth, the diameter of the LB core reaches $6.30 \mu \mathrm{m}-6.81 \mu \mathrm{m}$, depending on the value of $k_{2, F R}$. After another six months, the outer diameter of the halo reaches $11.1 \mu \mathrm{m}-11.6 \mu \mathrm{m}$.

An increase in the rate constant for the first pseudoelementary step of the F-W model describing nucleation of $\alpha$-syn aggregates, $k_{1, A S}$, leads to an increase of the nucleation rate of $\alpha$-syn aggregates (Fig. 6a). This leads to faster growth of the LB halo (Fig. 6b). After six months of growth, the diameter of the LB core reaches $6.34 \mu \mathrm{m}$. After another six months, the outer diameter of the halo reaches $10.2 \mu \mathrm{m}-11.7$ $\mu \mathrm{m}$, depending on the value of $k_{1, A S}$.

The increase of the rate constant for the second pseudoelementary step of the F-W model describing autocatalytic growth of $\alpha$-syn fibrils due to attachment of $\alpha$-syn monomers in the LB halo, $k_{2, A S}$, leads to 
an increase of autocatalytic growth of $\alpha$-syn fibrils (Fig. 7a). This leads to faster growth of the LB halo (Fig. 7b). As in Fig. 5, to produce distinctly different curves in Fig. 7 the value of $k_{2, A S}$ had to be increased by a factor of $10^{3}$. After six months of growth, the diameter of the LB core reaches $6.34 \mu \mathrm{m}$. After another six months, the outer diameter of the halo reaches $11.0 \mu \mathrm{m}-12.3 \mu \mathrm{m}$, depending on the value of $k_{2, A S}$.

\subsection{Investigating the sensitivity of the size of the LB to model parameters}

The relative sensitivity coefficients are reported in Table 4 . An important parameter predicted by the model is the outer halo radius at the end of the simulation, $r_{H, f}$. We investigated how $r_{H, f}$ depends on model parameters. The final radius of the LB is highly sensitive to the generation rates of membrane fragments and $\alpha$-syn monomers. Also, $r_{H, f}$ is sensitive to the rate constants for the first pseudoelementary steps of the F-W model describing nucleation of membrane fragment aggregates and $\alpha$-syn aggregates.

Table 4. Relative sensitivity of the outer halo radius at the end of the simulation $\left(t_{H, f}=1\right.$ year), $r_{H, f}$, to production rates of membrane fragments and $\alpha$-syn monomers and kinetic constants characterizing aggregation rates of membrane fragments and $\alpha$-syn monomers. Computations were performed using Eqs. (22) and (23) with (for example) $\Delta q_{F R}=10^{-3} q_{F R}$.

\begin{tabular}{|l|l|l|l|l|l|}
\hline$S_{q_{F R}}^{r_{H, f}}$ & $S_{q_{A S}}^{r_{H, f}}$ & $S_{k_{1, F R}}^{r_{H, f}}$ & $S_{k_{2, F R}}^{r_{H, f}}$ & $S_{k_{1, A S}}^{r_{H, f}}$ & $S_{k_{2, A S}}^{r_{H, f}}$ \\
\hline 0.193 & 0.437 & 0.0428 & 0.00333 & 0.0968 & 0.00753 \\
\hline
\end{tabular}

\section{Discussion, limitations of the model, and future directions}

The two main results obtained in this paper are the model of LB growth and an analytical solution of this model. The LB is assumed to consist of a core, which is composed of aggregated lipid membrane fragments, damaged organelles, lysosomes, and damaged mitochondria, and a halo, which is composed of radiating $\alpha$-syn filaments.

The developed model is minimalistic. Indeed, real LBs consist of more than 300 proteins [5]. More detailed mechanisms involved in the formation and growth of LBs need to be added in future research. Future research should develop a physical model explaining why the growth of a lipid core is replaced by 
the growth of a halo that is composed of radiating filaments. There is likely a critical radius of the core when such a change becomes thermodynamically favorable.

Data accessibility. This article has no additional data.

Authors' contributions. IAK and AVK contributed equally to the performing of computational work and article preparation. Both authors approved the final version of the manuscript and agreed to be accountable for all aspects of the work.

Competing interests. We have no competing interests.

Funding statement. IAK acknowledges the fellowship support of the Paul and Daisy Soros Fellowship for New Americans and the NIH/National Institute of Mental Health (NIMH) Ruth L. Kirchstein NRSA (F30 MH122076-01). AVK acknowledges the support of the National Science Foundation (award CBET2042834) and the Alexander von Humboldt Foundation through the Humboldt Research Award. 


\section{References}

1. Kalia LV, Lang AE. 2015 Parkinson's disease. Lancet 386, 896-912. (doi:10.1016/S01406736(14)61393-3)

2. Gomez-Benito M, Granado N, Garcia-Sanz P, Michel A, Dumoulin M, Moratalla R. 2020 Modeling Parkinson's disease with the alpha-synuclein protein. Frontiers in Pharmacology 11, 356. (doi:10.3389/fphar.2020.00356)

3. Mahul-Mellier A, Burtscher J, Maharjan N, Weerens L, Croisier M, Kuttler F, Leleu M, Knott GW, Lashuel HA. 2020 The process of Lewy body formation, rather than simply alpha-synuclein fibrillization, is one of the major drivers of neurodegeneration. Proc. Natl. Acad. Sci. U. S. A. 117, 4971-4982. (doi:10.1073/pnas.1913904117)

4. Spillantini M, Crowther R, Jakes R, Hasegawa M, Goedert M. 1998 Alpha-synuclein in filamentous inclusions of Lewy bodies from Parkinson's disease and dementia with Lewy bodies. Proc. Natl. Acad. Sci. U. S. A. 95, 6469-6473. (doi:10.1073/pnas.95.11.6469)

5. Shahmoradian SH, Lewis AJ, Genoud C, Hench J, Moors TE, Navarro PP, Castano-Diez D, Schweighauser G, Graff-Meyer A, Godie KN, Sutterlin R, Huisman E, Ingrassia A, de Gier Y, Rozemuller AJM, Wang J, De Paepe A, Erny J, Staempfli A, Hoernschemeyer J, Grosserueschkamp F, Niedieker D, El-Mashtoly SF, Quadri M, Van IJcken WFJ, Bonifati V, Gerwert K, Bohrmann B, Frank S, Britschgi M, Stahlberg H, Van de Berg WDJ, Lauer ME. 2019 Lewy pathology in Parkinson's disease consists of crowded organelles and lipid membranes. Nat. Neurosci. 22, 10991109. (doi:10.1038/s41593-019-0423-2)

6. Lashuel HA. 2020 Do Lewy bodies contain alpha-synuclein fibrils? and does it matter? A brief history and critical analysis of recent reports. Neurobiol. Dis. 141, 104876. (doi:10.1016/j.nbd.2020.104876)

7. Fares MB, Jagannath S, Lashuel HA. 2021 Reverse engineering Lewy bodies: How far have we come and how far can we go? Nature Reviews Neuroscience 22, 111-131. (doi:10.1038/s41583-02000416-6)

8. Shults C. 2006 Lewy bodies. Proc. Natl. Acad. Sci. U. S. A. 103, 1661-1668. (doi:10.1073/pnas.0509567103)

9. Power JHT, Barnes OL, Chegini F. 2017 Lewy bodies and the mechanisms of neuronal cell death in Parkinson's disease and dementia with lewy bodies. Brain Pathology 27, 3-12. (doi:10.1111/bpa.12344)

10. Olanow C, Perl D, DeMartino G, McNaught K. 2004 Lewy-body formation is an aggresome-related process: A hypothesis. Lancet Neurology 3, 496-503. (doi:10.1016/S1474-4422(04)00827-0)

11. Parkkinen L, O'Sullivan SS, Collins C, Petrie A, Holton JL, Revesz T, Lees AJ. 2011 Disentangling the relationship between Lewy bodies and nigral neuronal loss in Parkinson's disease. Journal of Parkinsons Disease 1, 277-286. (doi:10.3233/JPD-2011-11046) 
12. Gambinossi F, Mylon SE, Ferri JK. 2015 Aggregation kinetics and colloidal stability of functionalized nanoparticles. Adv. Colloid Interface Sci. 222, 332-349.

(doi:10.1016/j.cis.2014.07.015)

13. Bentea L, Watzky MA, Finke RG. 2017 Sigmoidal nucleation and growth curves across nature fit by the finke-watzky model of slow continuous nucleation and autocatalytic growth: Explicit formulas for the lag and growth times plus other key insights. Journal of Physical Chemistry C 121, 53025312. (doi:10.1021/acs.jpcc.6b12021)

14. Szabo R, Lente G. 2019 Full analytical solution of a nucleation-growth type kinetic model of nanoparticle formation. Journal of Mathematical Chemistry 57, 616-631. (doi:10.1007/s10910-0180975-5)

15. Yoon J, Jo W, Jeong D, Kim J, Jeong H, Park J. 2015 Generation of nanovesicles with sliced cellular membrane fragments for exogenous material delivery. Biomaterials 59, 12-20. (doi:10.1016/j.biomaterials.2015.04.028)

16. Nath S, Meuvis J, Hendrix J, Carl SA, Engelborghs Y. 2010 Early aggregation steps in alphasynuclein as measured by FCS and FRET: Evidence for a contagious conformational change. Biophys. J. 98, 1302-1311. (doi:10.1016/j.bpj.2009.12.4290)

17. Ruggeri FS, Benedetti F, Knowles TPJ, Lashuel HA, Sekatskii S, Dietler G. 2018 Identification and nanomechanical characterization of the fundamental single-strand protofilaments of amyloid alphasynuclein fibrils. Proc. Natl. Acad. Sci. U. S. A. 115, 7230-7235. (doi:10.1073/pnas.1721220115)

18. Sanchez SE, Whiten DR, Meisl G, Ruggeri FS, Hidari E, Klenerman D. 2021 Alpha synuclein only forms fibrils in vitro when larger than its critical size of 70 monomers. Chembiochem 22, 2867-2871. (doi:10.1002/cbic.202100285)

19. Beck JV, Arnold KJ. 1977 Parameter Estimation in Science and Engineering. New York: Wiley.

20. Zadeh KS, Montas HJ. 2010 A class of exact solutions for biomacromolecule diffusion-reaction in live cells. J. Theor. Biol. 264, 914-933. (doi:10.1016/j.jtbi.2010.03.028)

21. Zi Z. 2011 Sensitivity analysis approaches applied to systems biology models. Iet Systems Biology 5, 336-346. (doi:10.1049/iet-syb.2011.0015)

22. Kuznetsov IA, Kuznetsov AV. 2019 Investigating sensitivity coefficients characterizing the response of a model of tau protein transport in an axon to model parameters. Comput. Methods Biomech.

Biomed. Engin. 22, 71-83. (doi:10.1080/10255842.2018.1534233)

23. Kacser H, Burns J, Fell D. 1995 The control of flux. Biochem. Soc. Trans. 23, 341-366. (doi:10.1042/bst0230341)

24. Figure generated with the aid of servier medical art, licensed under a creative common attribution 3.0 generic license. http://smart.servier.com. 


\section{Figure captions}

Fig. 1. A diagram showing an LB composed of two regions: the central core composed of dense granular material and the halo containing radiating filaments (modeled after an electron micrograph shown in Fig. 1 in [10] and Fig. 3 in [7]) [24].

Fig. 2. (a) Molar concentration of aggregated lipid membrane fragments in the core of the LB, $\left[B_{F R}\right]$, and molar concentration of $\alpha$-syn fibrils in the halo of an LB, $\left[B_{A S}\right]$, versus time. (b) Radius of the core of the LB, $r_{L B}$, and the outer radius of the halo of the LB versus time, $r_{H}$, for three values of $q_{F R} \cdot q_{A S}=5 \times 10^{-27}$ $\mathrm{mol} \mathrm{s}^{-1}, k_{1, F R}=3 \times 10^{-7} \mathrm{~s}^{-1}, k_{2, F R}=2 \times 10^{-6} \mu \mathrm{M}^{-1} \mathrm{~s}^{-1}, k_{1, A S}=3 \times 10^{-7} \mathrm{~s}^{-1}, k_{2, A S}=2 \times 10^{-6} \mu \mathrm{M}^{-1} \mathrm{~s}^{-1}$. The MATLAB notation is utilized, i.e., 5 e- 27 means $5 \times 10^{-27}$.

Fig. 3. (a) Molar concentration of aggregated lipid membrane fragments in the core of the $L B,\left[B_{F R}\right]$, and molar concentration of $\alpha$-syn fibrils in the halo of the LB, $\left[B_{A S}\right]$, versus time. (b) Radius of the core of the LB, $r_{L B}$, and the outer radius of the halo of the LB versus time, $r_{H}$, for three values of $q_{A S}$.

$$
q_{F R}=5 \times 10^{-27} \mathrm{~mol} \mathrm{~s}^{-1}, k_{1, F R}=3 \times 10^{-7} \mathrm{~s}^{-1}, k_{2, F R}=2 \times 10^{-6} \mu \mathrm{M}^{-1} \mathrm{~s}^{-1}, k_{1, A S}=3 \times 10^{-7} \mathrm{~s}^{-1}, k_{2, A S}=2 \times 10^{-6} \mu \mathrm{M}^{-1}
$$
$\mathrm{S}^{-1}$.

Fig. 4. (a) Molar concentration of aggregated lipid membrane fragments in the core of the $L B,\left[B_{F R}\right]$, and molar concentration of $\alpha$-syn fibrils in the halo of the LB, $\left[B_{A S}\right]$, versus time. (b) Radius of the core of the LB, $r_{L B}$, and the outer radius of the halo of the LB versus time, $r_{H}$, for three values of $k_{1, F R}$. $q_{F R}=5 \times 10^{-27} \mathrm{~mol} \mathrm{~s}^{-1}, q_{A S}=5 \times 10^{-27} \mathrm{~mol} \mathrm{~s}^{-1}, k_{2, F R}=2 \times 10^{-6} \mu \mathrm{M}^{-1} \mathrm{~s}^{-1}, k_{1, A S}=3 \times 10^{-7} \mathrm{~s}^{-1}, k_{2, A S}=2 \times 10^{-6}$ $\mu \mathrm{M}^{-1} \mathrm{~s}^{-1}$.

Fig. 5. (a) Molar concentration of aggregated lipid membrane fragments in the core of the $L B,\left[B_{F R}\right]$, and molar concentration of $\alpha$-syn fibrils in the halo of the LB, $\left[B_{A S}\right]$, versus time. (b) Radius of the core of the LB, $r_{L B}$, and the outer radius of the halo of the LB versus time, $r_{H}$, for three values of $k_{2, F R}$.

$$
q_{F R}=5 \times 10^{-27} \mathrm{~mol} \mathrm{~s}^{-1}, q_{A S}=5 \times 10^{-27} \mathrm{~mol} \mathrm{~s}^{-1}, k_{1, F R}=3 \times 10^{-7} \mathrm{~s}^{-1}, k_{1, A S}=3 \times 10^{-7} \mathrm{~s}^{-1}, k_{2, A S}=2 \times 10^{-6} \mu \mathrm{M}^{-1} \mathrm{~s}^{-}
$$


Fig. 6. (a) Molar concentration of aggregated lipid membrane fragments in the core of the LB, $\left[B_{F R}\right]$, and molar concentration of $\alpha$-syn fibrils in the halo of the LB, $\left[B_{A S}\right]$, versus time. (b) Radius of the core of the LB, $r_{L B}$, and the outer radius of the halo of the LB versus time, $r_{H}$, for three values of $k_{1, A S}$.

$q_{F R}=5 \times 10^{-27} \mathrm{~mol} \mathrm{~s}^{-1}, q_{A S}=5 \times 10^{-27} \mathrm{~mol} \mathrm{~s}^{-1}, k_{1, F R}=3 \times 10^{-7} \mathrm{~s}^{-1}, k_{2, F R}=2 \times 10^{-6} \mu \mathrm{M}^{-1} \mathrm{~s}^{-1}, k_{2, A S}=2 \times 10^{-6}$ $\mu \mathrm{M}^{-1} \mathrm{~s}^{-1}$.

Fig. 7. (a) Molar concentration of aggregated lipid membrane fragments in the core of the LB, $\left[B_{F R}\right]$, and molar concentration of $\alpha$-syn fibrils in the halo of the LB, $\left[B_{A S}\right]$, versus time. (b) Radius of the core of the LB, $r_{L B}$, and the outer radius of the halo of the LB versus time, $r_{H}$, for three values of $k_{2, A S}$.

$$
q_{F R}=5 \times 10^{-27} \mathrm{~mol} \mathrm{~s}^{-1}, q_{A S}=5 \times 10^{-27} \mathrm{~mol} \mathrm{~s}^{-1}, k_{1, F R}=3 \times 10^{-7} \mathrm{~s}^{-1}, k_{2, F R}=2 \times 10^{-6} \mu \mathrm{M}^{-1} \mathrm{~s}^{-1}, k_{1, A S}=3 \times 10^{-7} \mathrm{~s}^{-}
$$




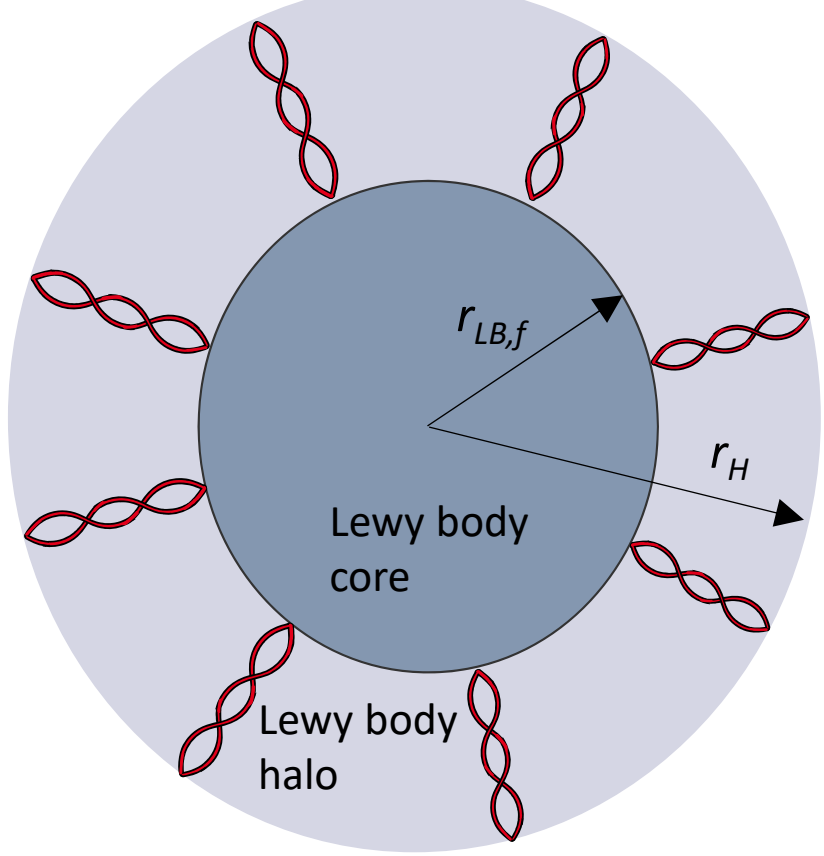

Figure 1

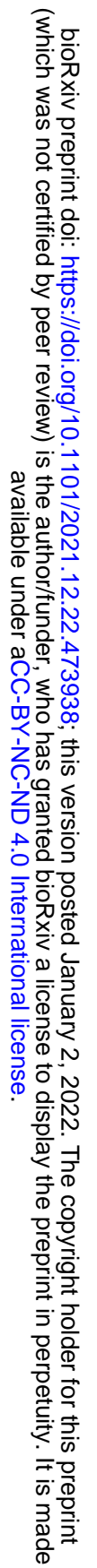


bioRxiv preprint doi: https://doi org/10.1101/2021.12.22.473938; this version posted January 2, 2022. The copyright holder for this preprint (which was not certified by peer review) is the author/funder, who has granted bioRxiv a license to display the preprint in perpetuity. It is made available under aCC-BY-NC-ND 4.0 International license.

(a)

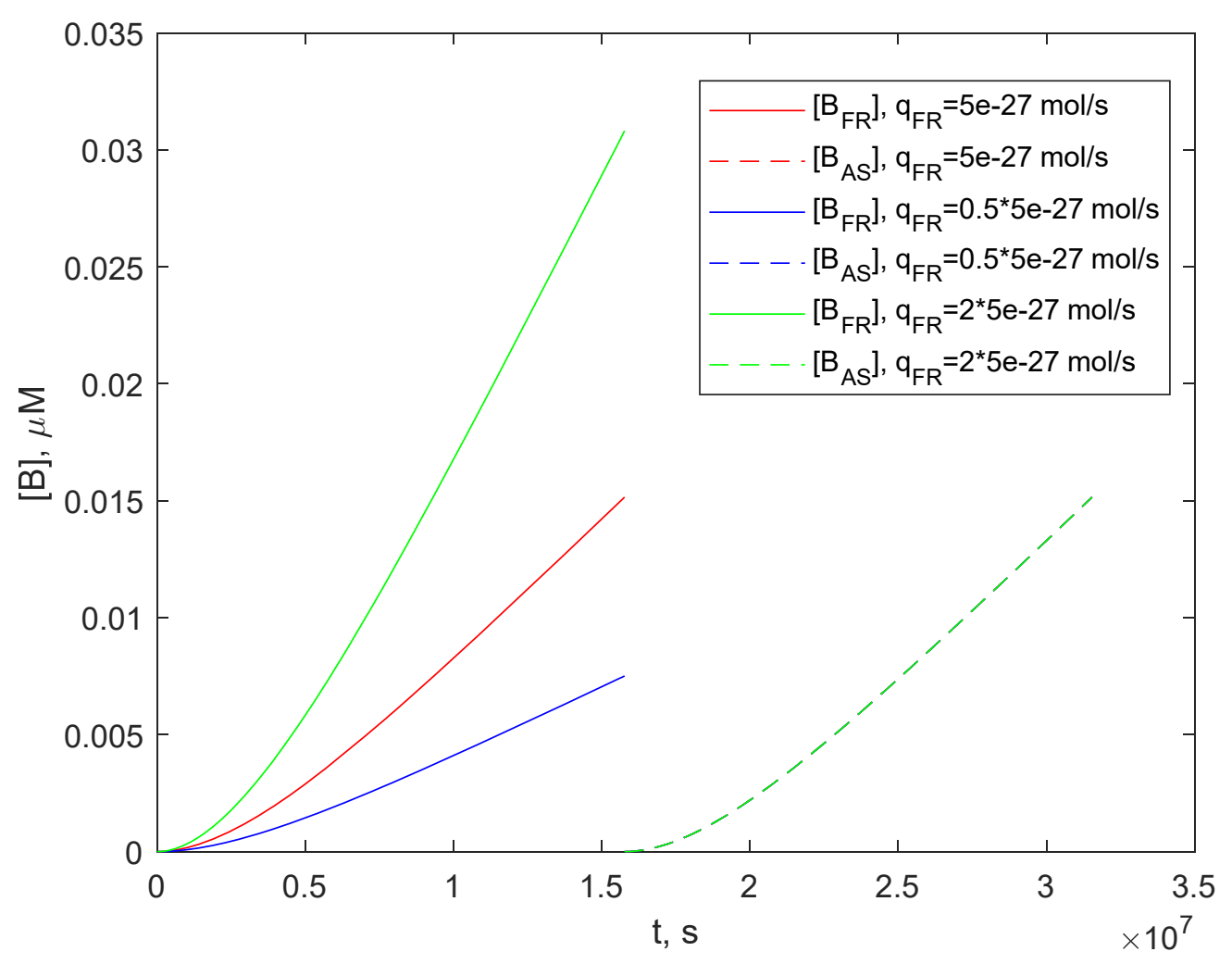

(b)

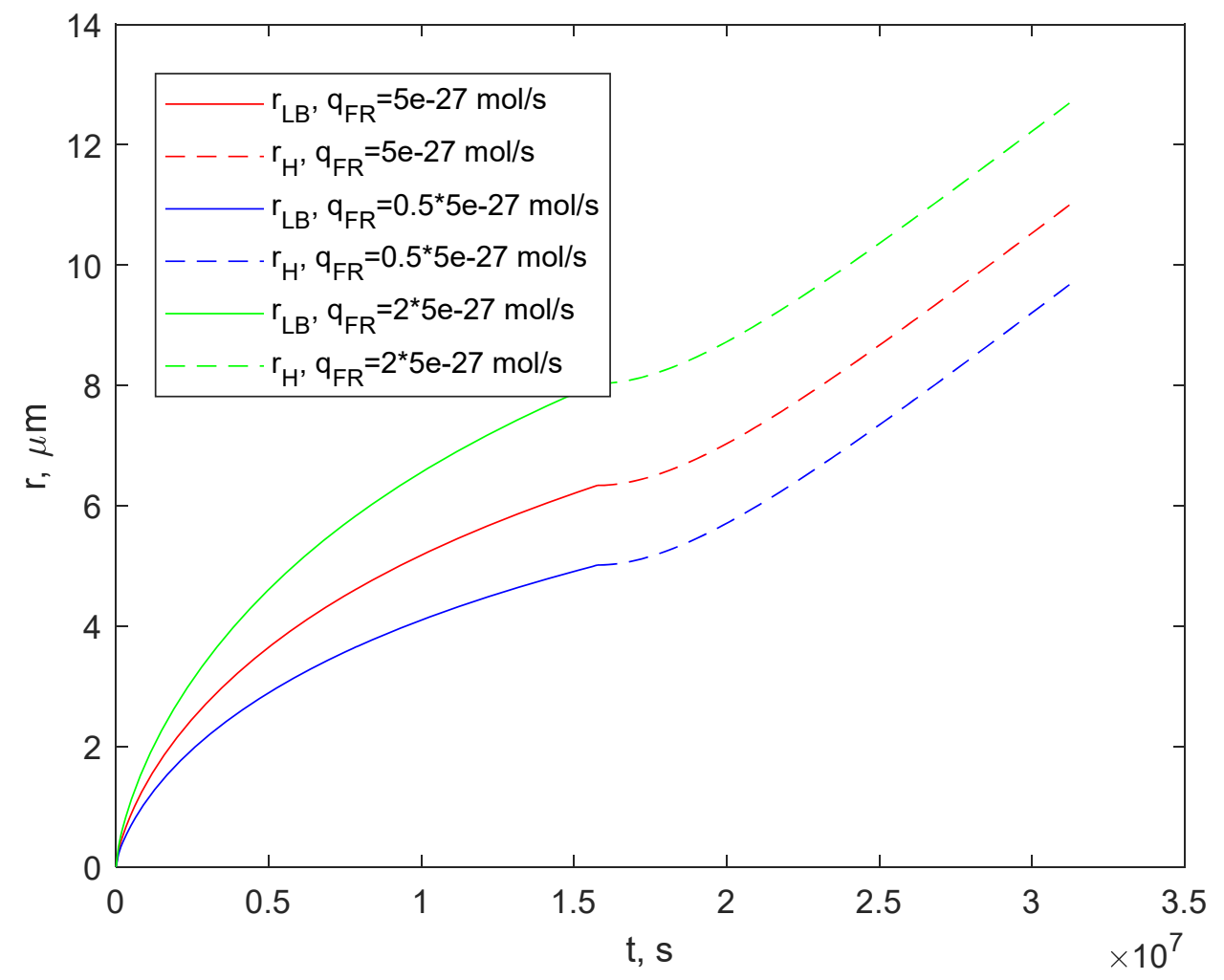

Figure 2 
bioRxiv preprint doi: https://doi.org/10.1101/2021.12.22.473938; this version posted January 2, 2022. The copyright holder for this preprint (which was not certified by peer review) is the author/funder, who has granted bioRxiv a license to display the preprint in perpetuity. It is made available under aCC-BY-NC-ND 4.0 International license.

(a)

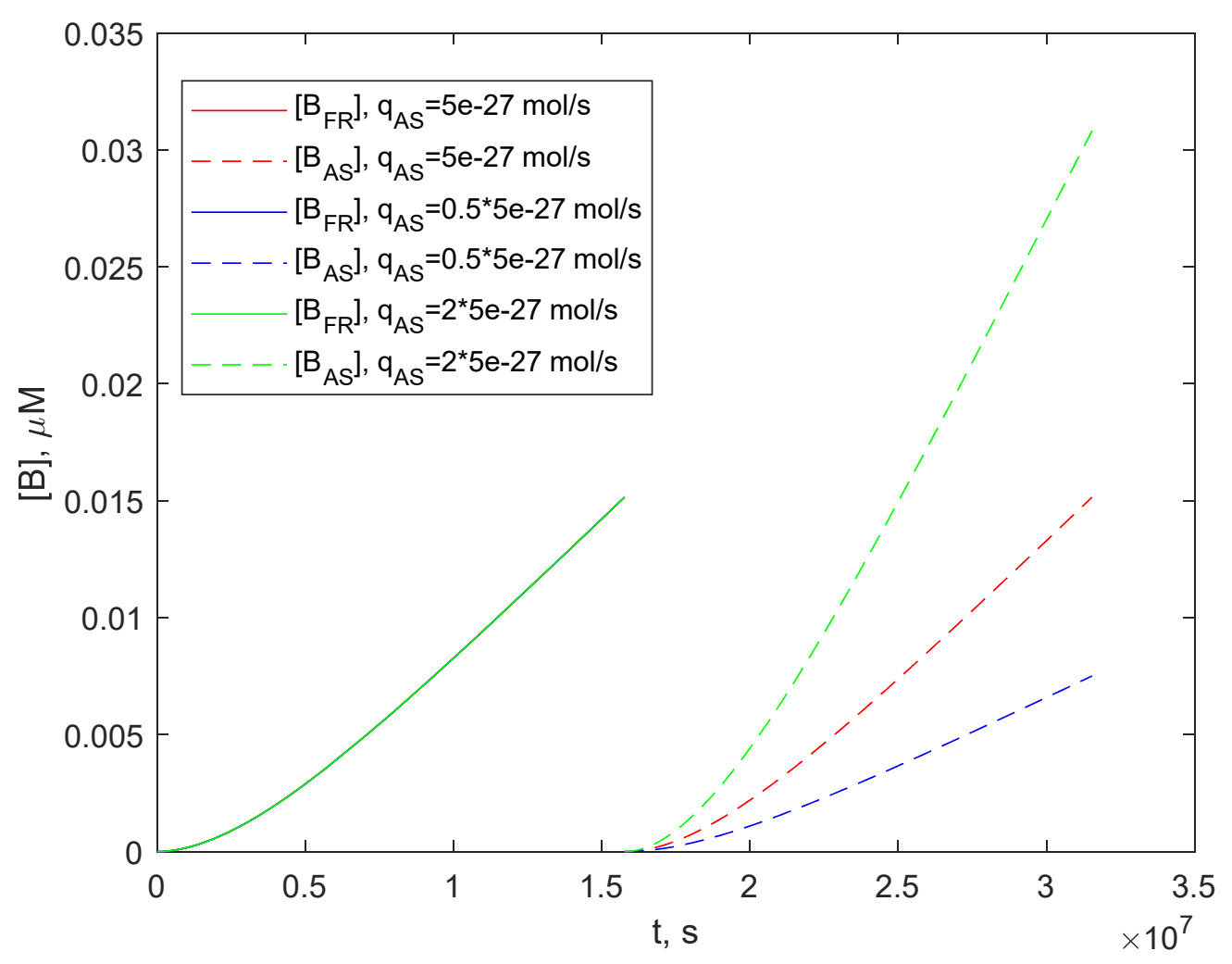

(b)

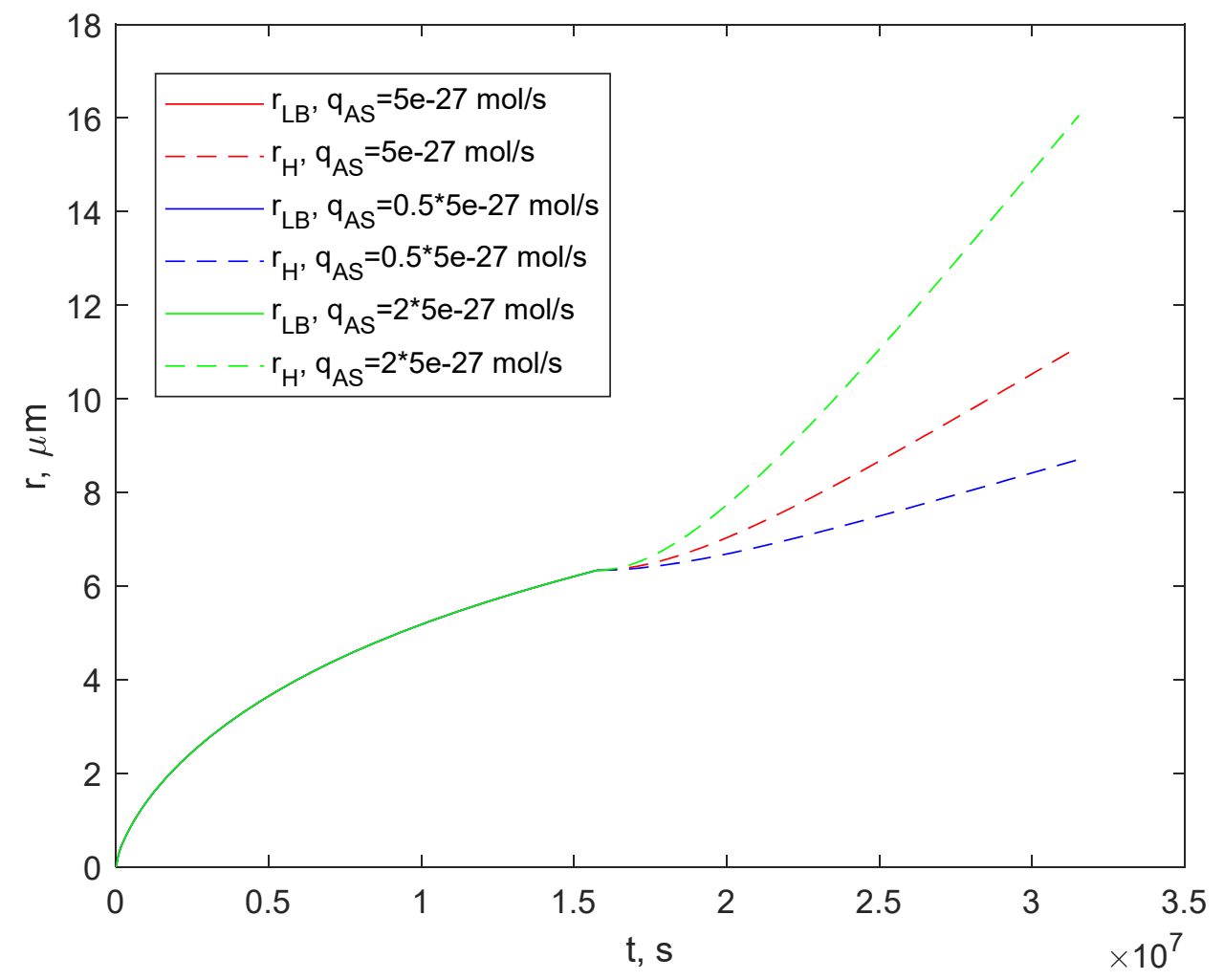

Figure 3 
(a)

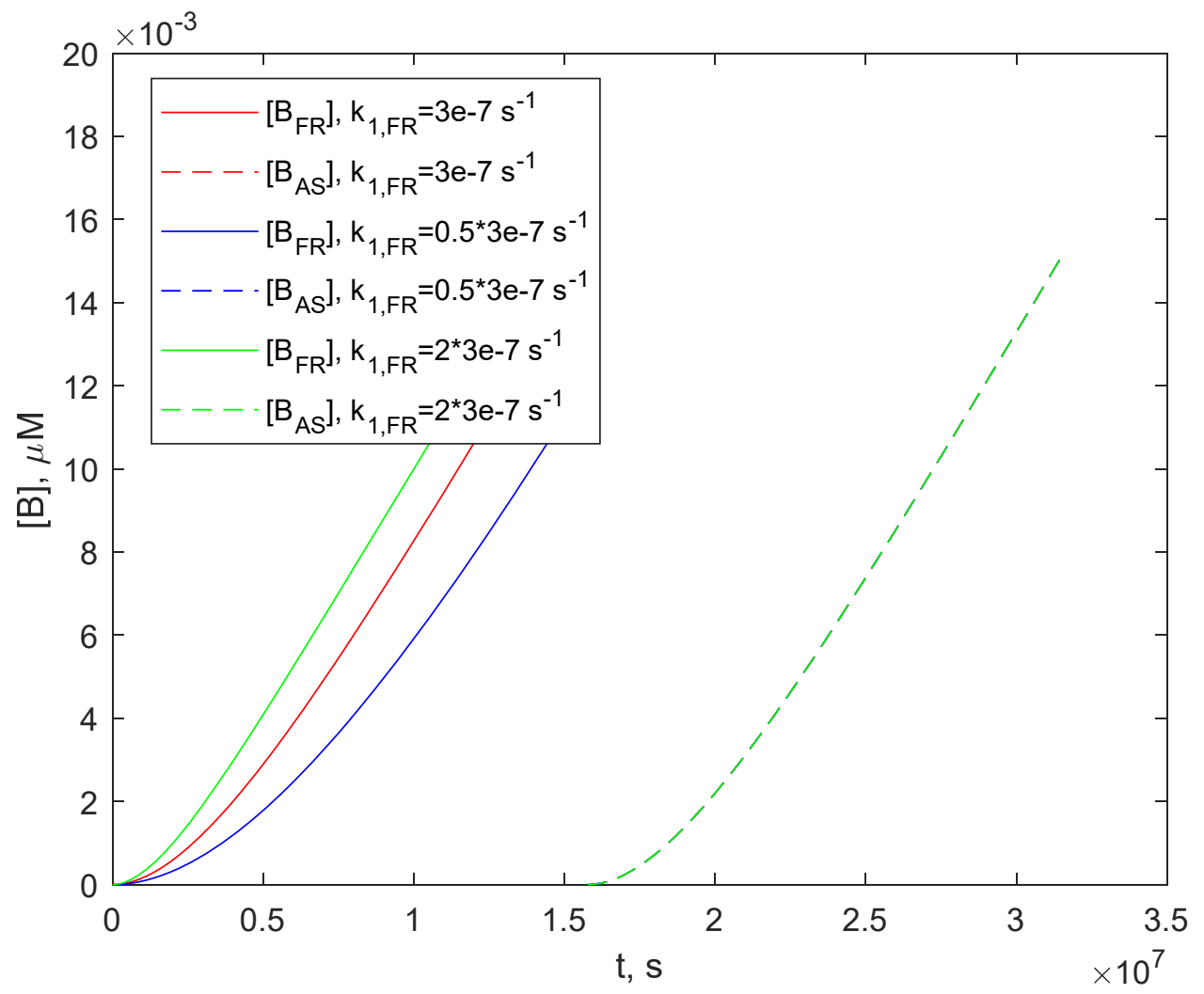

(b)

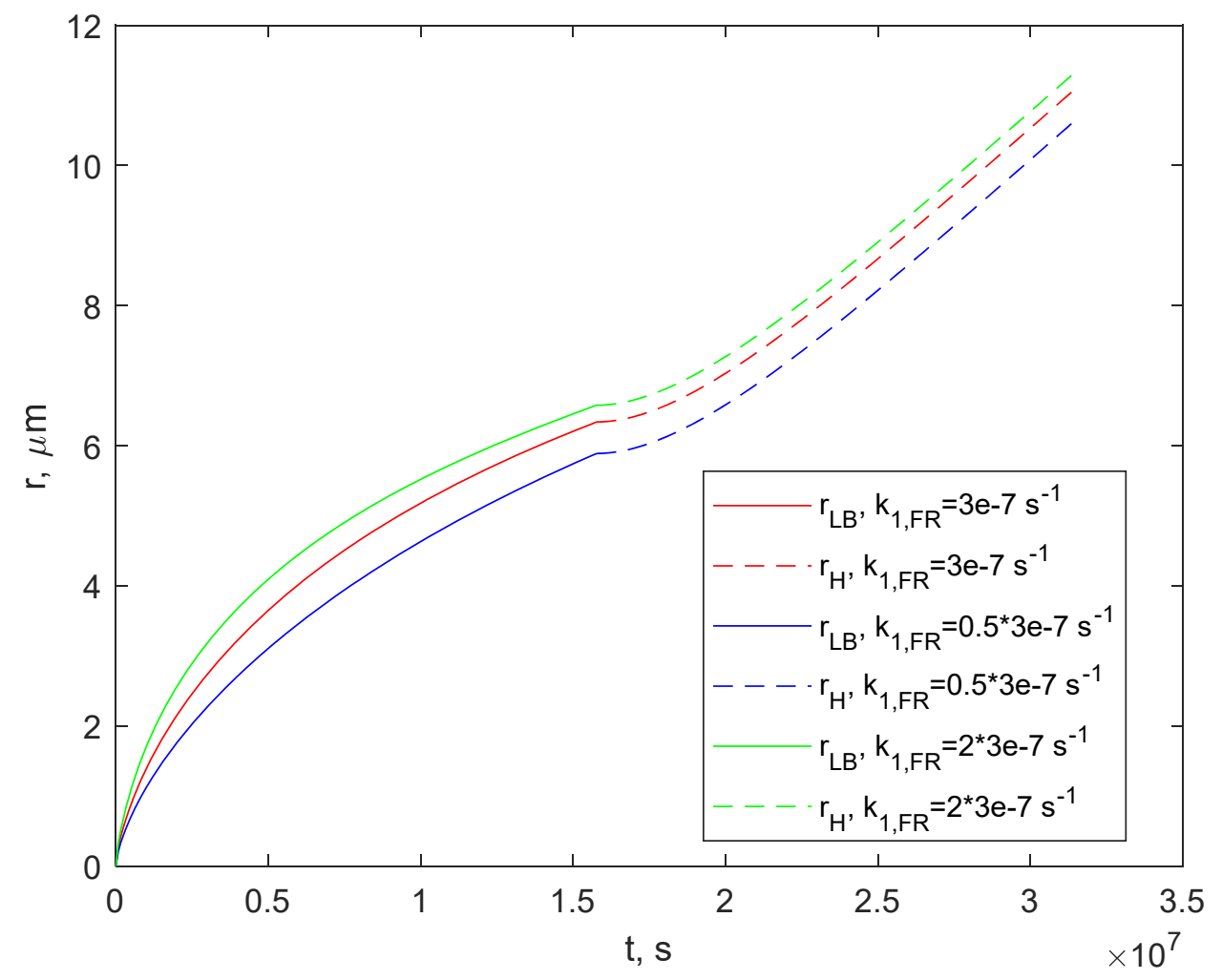


(a)

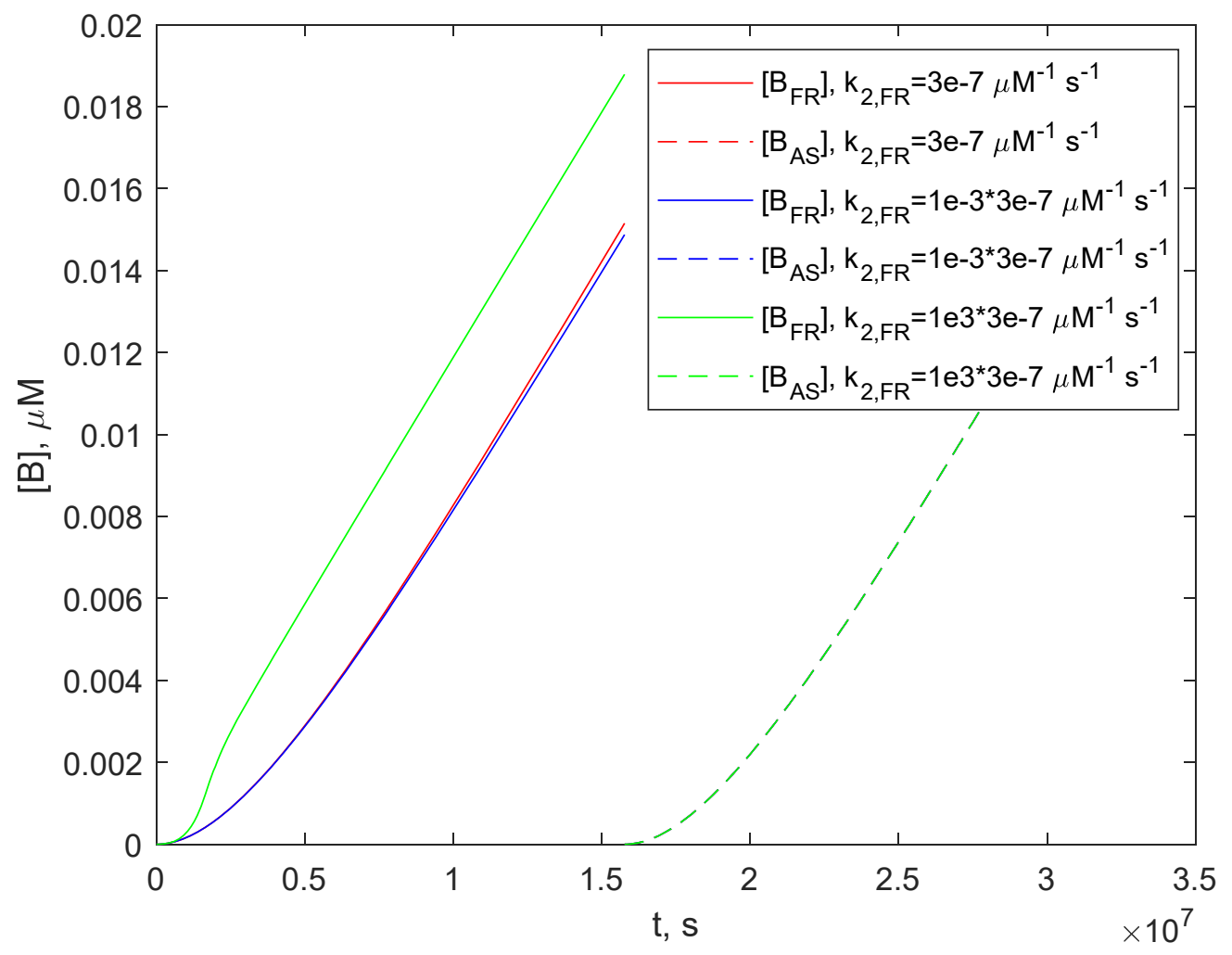

(b)

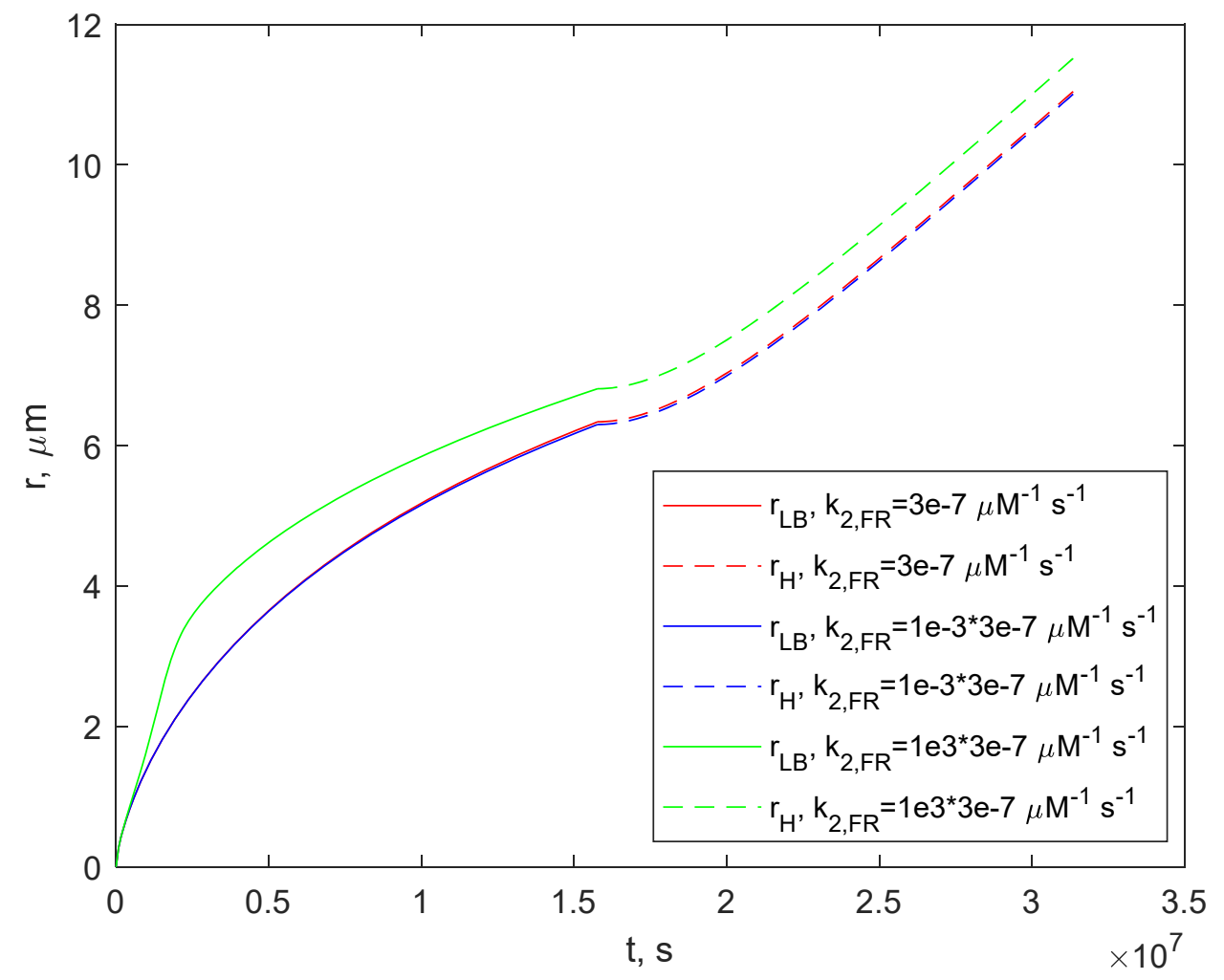

Figure 5 
(a)

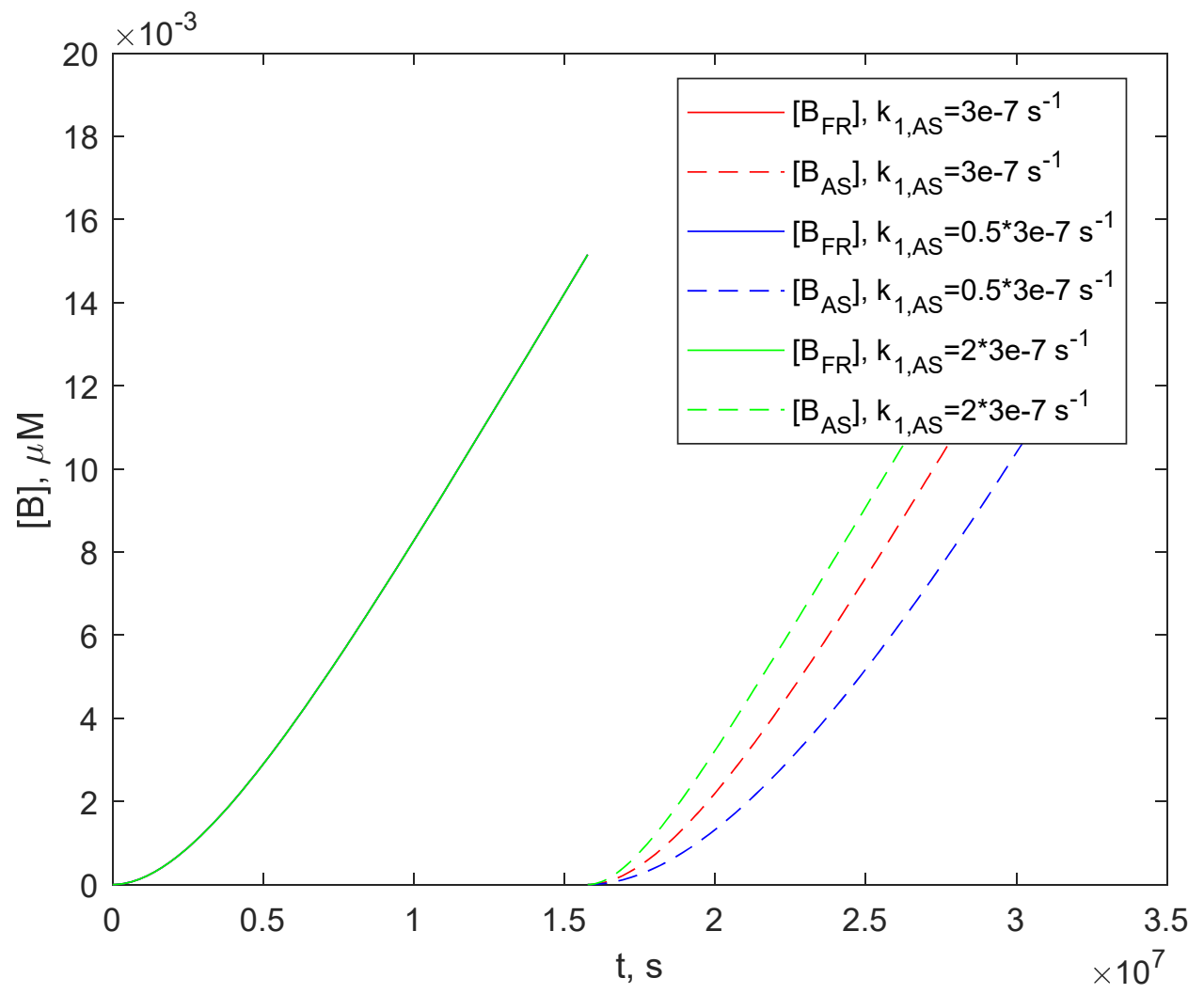

(b)

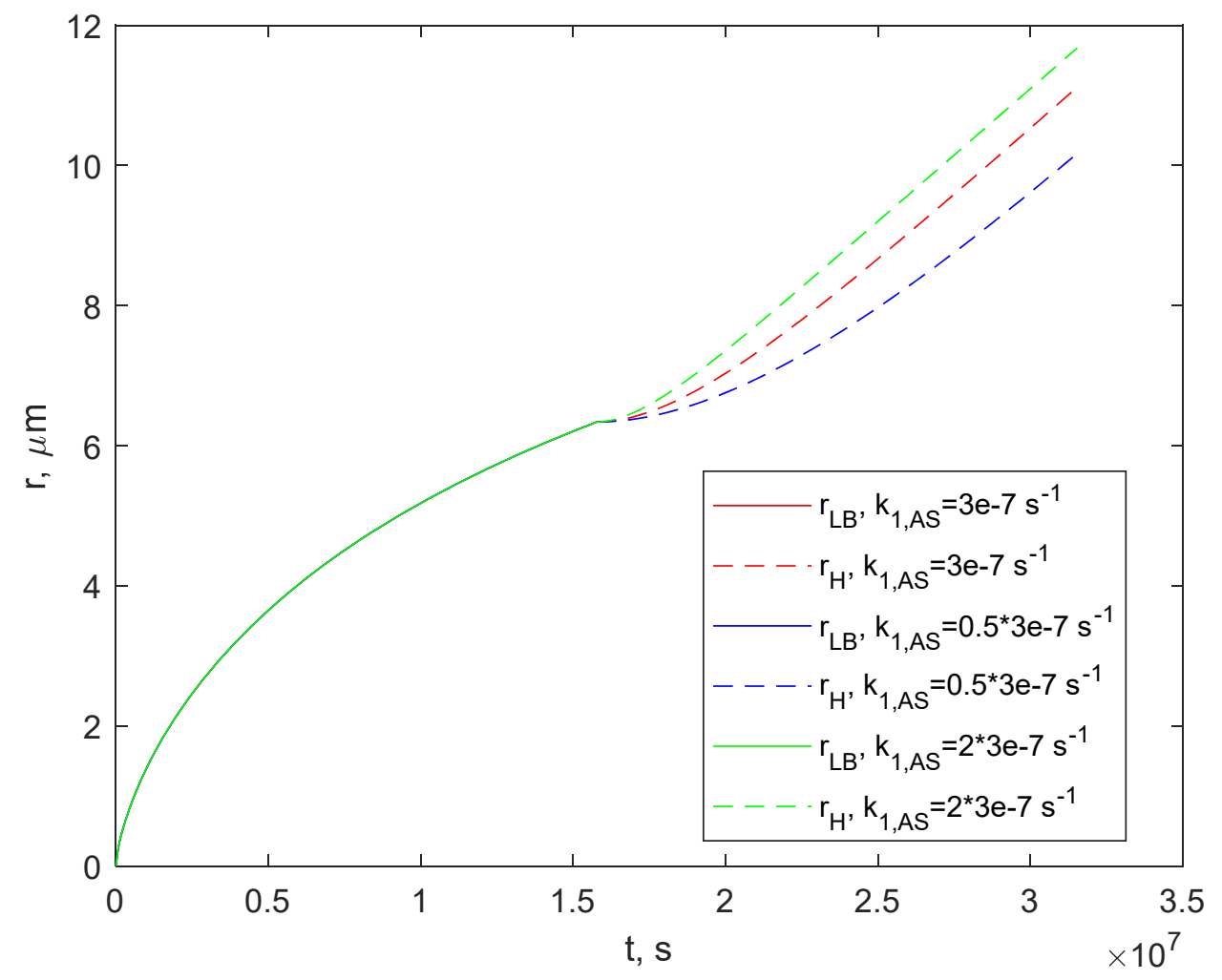

Figure 6 
(a)

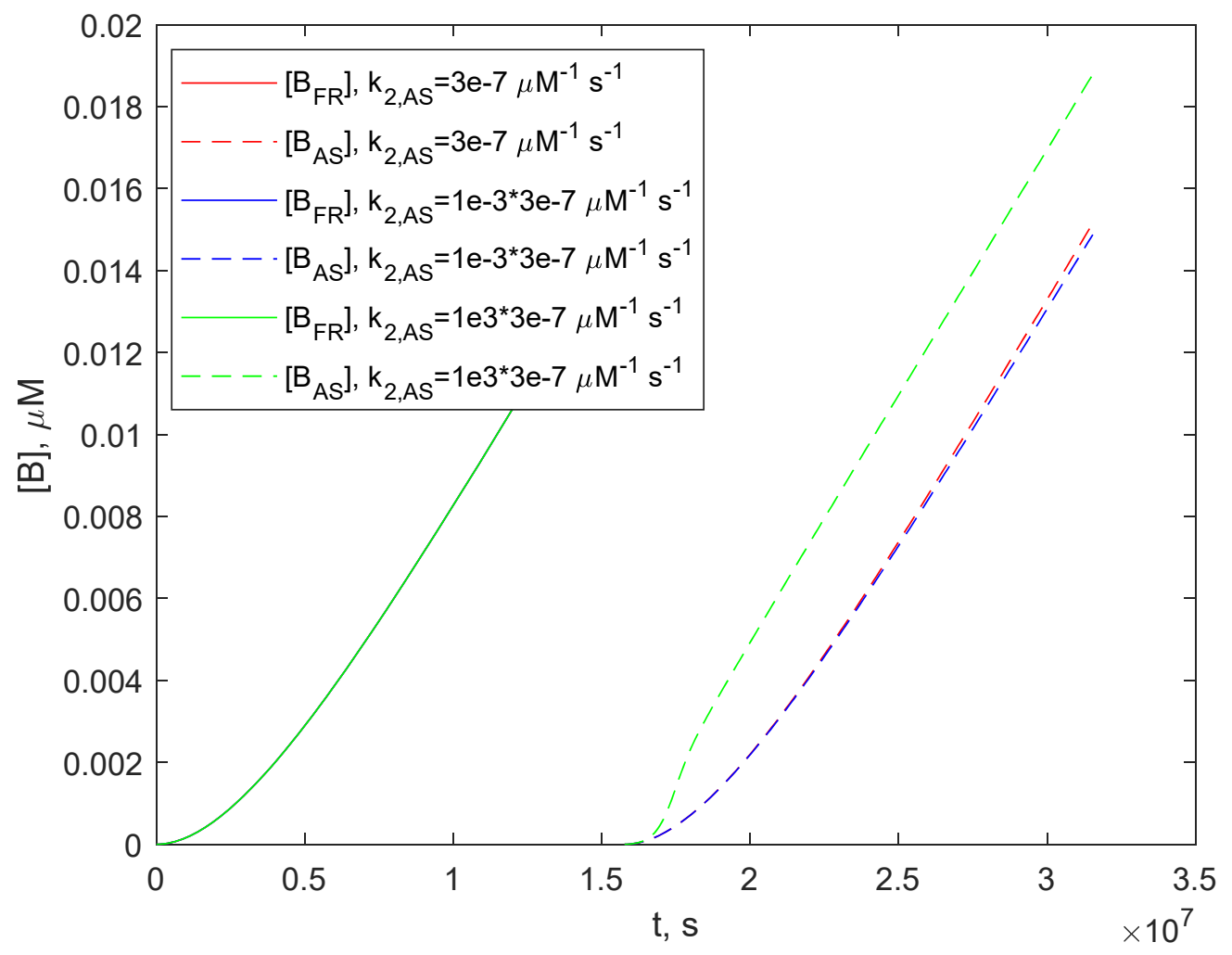

(b)

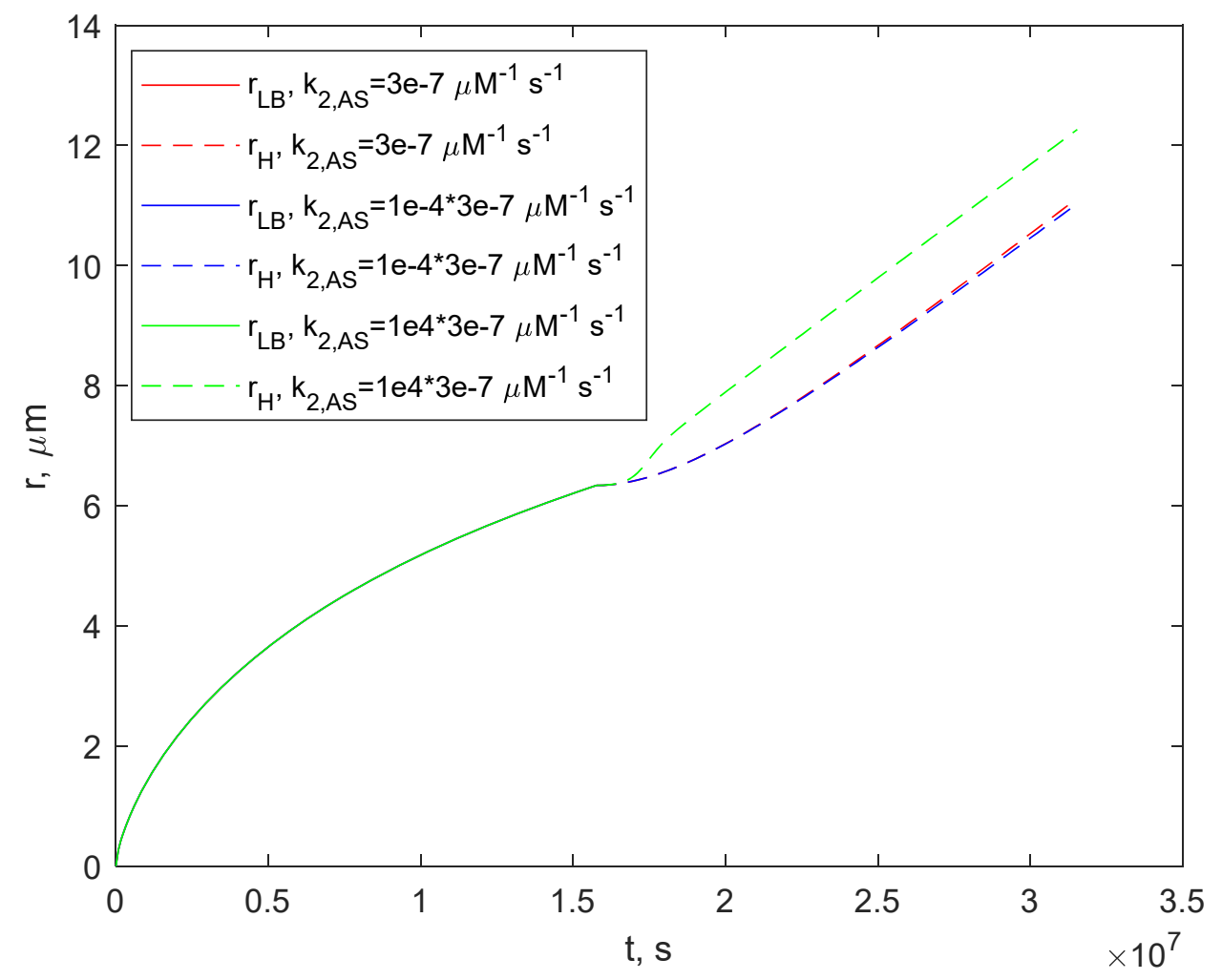

Figure 7 